\title{
Penile Reconstruction: Current Thoughts, Techniques, and Outcomes
}

Our Editor's Pick for EMJ Urology 8.1 is this review paper by Brazio et al. Availability and incidence of penile reconstructive surgeries has increased, with techniques refined over recent years to reduce complication rates. This article provides a detailed review of surgical techniques, including choice of reconstructive flaps and potential complications. As greater numbers of reconstructive surgeries are performed, this review provides valuable insight for urologists and plastic surgeons.

Authors:

Philip S. Brazio, Irene T. Ma, Jeff J. Kim, *Gordon K. Lee

Division of Plastic and Reconstructive Surgery, Stanford University School of

Medicine, Stanford, California, USA

*Correspondence to glee@stanford.edu

Disclosure: $\quad$ The authors have declared no conflicts of interest.

Received: $\quad 02.12 .2019$

Accepted: $\quad 11.02 .2020$

Keywords: $\quad$ Anterolateral thigh flap, bottom surgery, gender-affirming surgery, genderconfirming surgery, metoidioplasty, phalloplasty, radial forearm free flap, transgender, transsexual.

Citation: EMJ Urol. 2020;8[1]:12-21.

\section{Abstract}

Phalloplasty has matured considerably over the last decades in reconstructive options and technical refinements, thanks to increasing recognition of gender dysphoria. The primary goals of performing a phalloplasty are to facilitate sexual penetration, protective sensation, orgasm, standing micturition, and natural aesthetic, ideally in few stages and with minimal morbidity. Radial forearm free flap, anterolateral flap, and metoidioplasty are the most common options, each with a unique profile of complications, aesthetic, and functional outcomes. Choices for reconstruction must be tailored to the individual patient's goals and available tissue characteristics.

\section{INTRODUCTION}

Phalloplasty may be performed for penile trauma, congenital defects, or for gender dysphoria.,2 While phalloplasty for trauma ${ }^{3}$ or for microphallus ${ }^{4}$ remains relatively rare, phalloplasty has seen a steady rise in recent years with increasing recognition of gender dysphoria. ${ }^{5,6}$ An estimated $0.6 \%$ of the world's population identifies as transgender. Gender-affirming genital surgery is on the rise: from 2006 to 2011, 83.9\% of patients undergoing gender-affirming surgery underwent genital surgery. ${ }^{6}$

Generally speaking, goals of phalloplasty include the facilitation of sexual penetration, protective sensation, orgasm, standing micturition, and natural aesthetics. ${ }^{7}$ Additionally, the ideal choice of reconstructive method would have few stages and minimal morbidity. ${ }^{8}$ 


\section{PREOPERATIVE EVALUATION}

As with any elective reconstructive procedure, initial discussion with the patient should focus on their priorities for surgery, as well as setting expectations for potentially suboptimal outcomes and relatively high risks and rates of complications.

Gender-affirming phalloplasty in particular merits careful consideration. A detailed discussion of preoperative evaluation for gender-affirming surgery is beyond the scope of this article. Evaluation requires co-ordination between specialists from various fields including social work, psychiatry, endocrinology, urology, and plastic surgery. Version 7 of the Standards of Care for the Health of Transsexual, Transgender, and Gender Nonconforming People by the
World Professional Association for Transgender Health (WPATH) for phalloplasty/genital surgery ${ }^{9}$ specifies the preoperative requirements for surgery.

For nongender-confirming surgery, careful assessment of the preoperative penile functional and anatomical deficit, especially for cases after trauma, is paramount for the choice of reconstruction. In some rare instances, transplantation may also be an option..$^{10}$ Combined with a physical exam of potential donor sites, initial discussion allows honing into a method of reconstruction. If a microsurgical method is planned, the patient should be in good enough health to safely undergo a long procedure. Depending on the donor site, preoperative weight loss, hair/tattoo removal, and other preparations may be necessary.

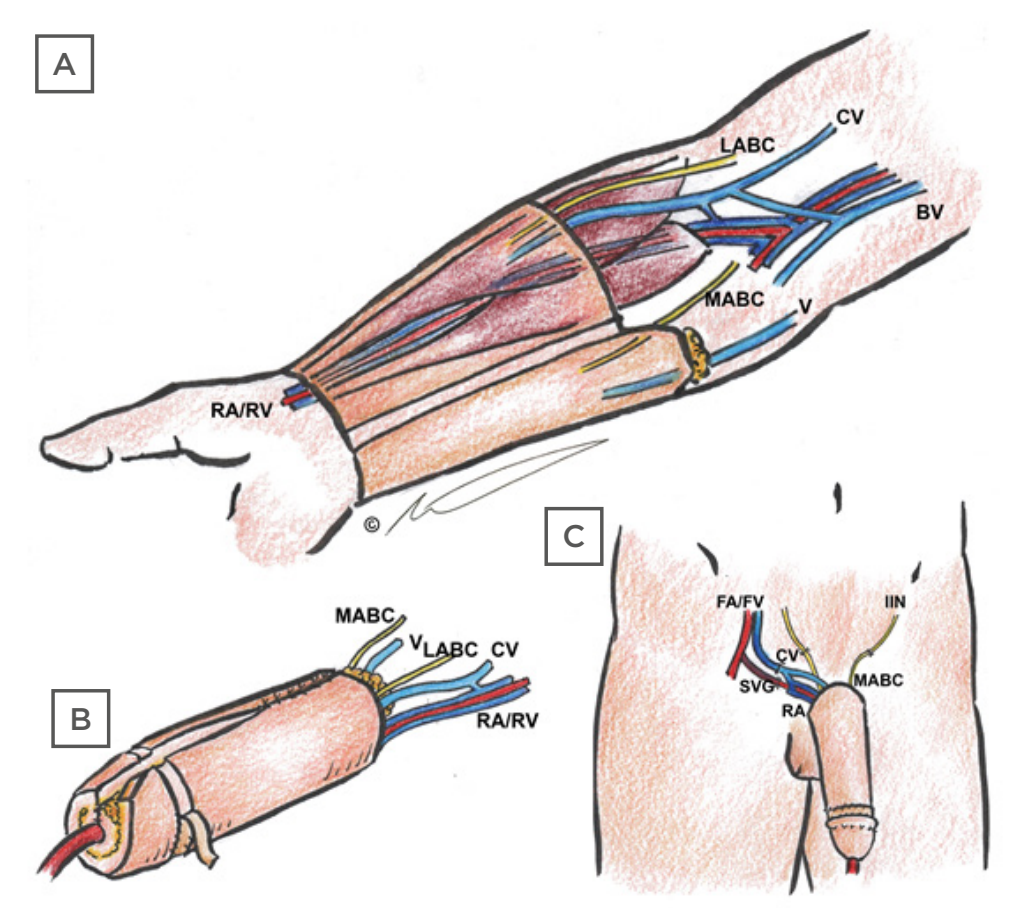

Figure 1: Schematic views of radial forearm flap phalloplasty.

(A) Anatomy of the flap in the arm including urethral (ulnar) segment with cuff of subcutaneous fat, external (radial), and de-epithelialised segments, the radial artery and vein emerging between brachioradialis and flexor carpi radialis muscles, lateral and medial antebrachial cutaneous nerves, cephalic and basilic veins, and unnamed superficial vein. (B) Fabrication of tube-in-tube neourethra showing partial tubularisation, as well as skin grafting from the de-epithelialised segment behind the neocoronal ridge in preparation for coronaplasty. (C) in situ appearance after single-stage phalloplasty showing anastomosis of the cephalic vein and radial artery to femoral vein and femoral artery via saphenous vein graft, respectively; as well as coaptation of the medial antebrachial cutaneous nerve to the ilioinguinal nerve.

BV: basilic veins; CV: cephalic veins; FA: femoral artery; FV: femoral vein; IIN: ilioinguinal nerve; LABC: lateral antebrachial cutaneous nerves; MABC: medial antebrachial cutaneous nerves; RA: radial artery; RV: radial vein; SVG: saphenous vein graft; $\vee$ : unnamed superficial vein. 


\section{SURGICAL TECHNIQUES AND OUTCOMES}

\section{Radial Forearm Free Flap}

Free radial forearm flap (RFF) is most commonly used for contemporary phalloplasty." Biemer et al. ${ }^{12}$ reported its use in transgender males in the early 1980s incorporating a portion of the radius as a stiffener, coapting nerves for sensation, and fabricating the urethra with a skin graft. In 1984, Chang and Hwang ${ }^{13}$ reported a single stage tubewithin-a-tube design of the RFF, which decreased urethral complications from previous methods of reconstruction. ${ }^{14}$ Further refinements have been added in the three decades since (Figure 1).

\section{Preoperatively, an Allen's test should be} performed. Patients should undergo complete preoperative electrolysis or laser hair removal of the donor side arm to minimise hair on the final construct; if this is impossible, flap design should place the neourethra in an area with the least amount of hair (usually the ulnar half of the forearm).

While there are variations on the design, the authors prefer centrally placing the neourethra in continuity with a neoglans to avoid circumferential meatal suture lines without sacrificing length. 13,15 The dimensions of the flap depend on the patient's desires and the available tissue; the thicker the tissue, the wider the flap to allow tube-within-atube construction. Minimum dimensions are 15×17 $\mathrm{cm}$. A proximal extension of the neourethra of 4-5 $\mathrm{cm}$ should be incorporated in gender-affirming surgery. ${ }^{14}$ This allows for more anterior and cephalad position of the base of the neophallus without tension on the urethral anastomosis.

The radial artery and venae comitantes are identified distally at the wrist and followed proximally, preserving septocutaneous perforators while ligating muscular and periosteal branches. Care is taken to include the superficial venous system, which is drained by the cephalic vein radially. Ulnar superficial branches may be included, but the basilic vein should be preserved if possible, to preserve venous outflow of the arm. The artery is dissected proximally until the bifurcation of the brachial artery. Venae comitantes are dissected until the two veins coalesce into one. If this dissection is continued more proximally, the coalesced vena comitans will join the cephalic vein via the profundus cubitalis vein, which allows for drainage of superficial and deep venous systems through one large calibre vessel. Dual venous anastomosis and outflow is an important tool to limit congestion and partial flap necrosis. The medial, lateral, and possibly posterior antebrachial cutaneous nerves, are identified and dissected an additional 3-4 cm proximal to the skin paddle to allow for tensionless coaptation at the recipient site. ${ }^{15,16}$

The femoral or the deep epigastric system can be used for flap inflow and outflow. 16,17 The authors prefer the femoral system, creating an arteriovenous loop using $20 \mathrm{~cm}$ or more of the great saphenous vein, and anastomosing to the superficial femoral artery in end to side fashion. Large saphenous vein tributaries are usually available for secondary drainage via the basilic vein. Epineurial neurorrhaphy is performed between the lateral antebrachial cutaneous nerve and the dorsal nerve of the penis/clitoral or the deep pudendal nerve, allowing for erogenous sensation. If medial or posterior antebrachial cutaneous nerves are included in the flap, they can additionally be coapted with the ilioinguinal or other sensory nerves to provide tactile sensation. The medial antebrachial cutaneous nerve may be less preferable if it innervates the urethral segment. $14,15,18$

The skin over the shaft of the clitoris is incised to identify the dorsal clitoral nerves before the clitoris is de-epithelialised and buried at the base of the neophallus. ${ }^{19}$ Finally, urethral lengthening is performed by inverting and tubularising the adjacent mucosal surface of vagina and labia minora in continuity with the native urethral opening. This allows the neophallus construct to sit in a more appropriate anterocephalad position on the pelvis after urethral anastomosis. ${ }^{14}$ The urethra is anastomosed end-to-end over a Foley catheter. De-epithelialised edges around the proximal neourethra can be used to reinforce the anastomosis.

There are many variations of RFF phalloplasty; some prefer to create the neoglans through the Norfolk procedure consisting of a rolled skin flap and split-thickness graft. ${ }^{19}$ Part of the radial bone can be harvested as osteocutaneous free flap for rigidity rather than placing a prosthesis. ${ }^{16,17}$ Exact 
nuances depend on the surgeon experience and preference.

Compared to other methods of reconstruction, RFF are relatively well reported in the literature and demonstrate overall favourable subjective and objective results. ${ }^{20-22}$ However, a paucity of high quality, comparative data on long-term surgical outcomes should lead to a provisional perspective on reported results. ${ }^{11}$

The aesthetic quality of the phallus has been rated highly by RFF phalloplasty patients, higher than surgeon or independent observer ratings. ${ }^{20-22}$ In a recent systematic review, 70-80\% reported overall satisfactory aesthetic outcome of the neophallus, usually $7.5-14.0 \mathrm{~cm}$ in length. ${ }^{2,11}$ The RFF can maintain exquisite sensitivity. ${ }^{2}$ Erogenous and tactile sensitivity have been maintained, with a significant portion of patients engaged in sexual activity being able to achieve an orgasm. ${ }^{21,23}$

The primary disadvantage of the RFF is donorsite morbidity, requiring a large skin graft for coverage. Many patients choose other methods for this reason because the RFF donor site scar can be associated with social stigma.,211,24-26 Other disadvantages include length and complexity of a microsurgical procedure, potential for total and partial flap loss, as well as other less common but certainly possible donor site morbidities, including possibly permanent hand dysfunction, prolonged hand swelling and lymphoedema, and need for regrafting of the arm defect. 2,24

The complication rate of RFF phalloplasty is reported as higher than other reconstructive options. ${ }^{2,24}$ Urethral complications are the most common, as they are with other methods, with urethral fistula rates of $15-77 \%$ and stricture and stenosis rates of $21-51 \% .^{27}$ Other common complications include wound healing issues, need for anastomotic revision, partial flap necrosis, and complications related to prostheses.

\section{Anterolateral Thigh Flap}

The anterolateral thigh (ALT) flap is a reliable option for reconstructive phalloplasty. It provides adequate shape and bulk, sensation, a long vascular pedicle, possibility for erectile prosthesis placement, minimal donor site morbidity, colour match, and a concealable scar. ${ }^{28-30}$ The standard technique for ALT flap design and perforator location can allow consistent dissection. ${ }^{31}$

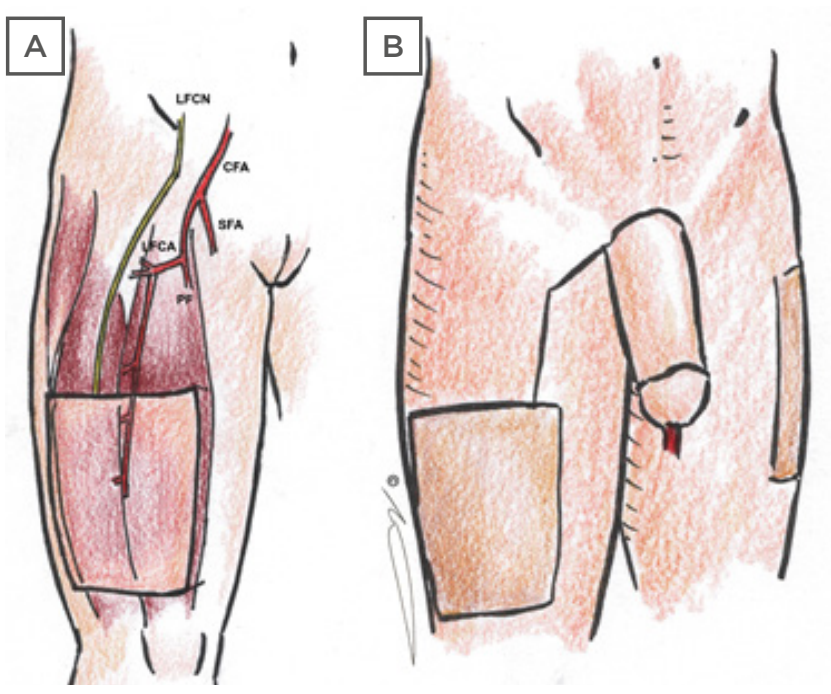

Figure 2: Schematic views of anterolateral thigh phalloplasty.

(A) Anatomy of the flap in the leg (without tube in tube urethral design), showing lateral femoral cutaneous nerve branch, common femoral artery, superficial femoral artery, profunda femoris, lateral femoral circumflex artery, and from lateral to medial the tensor fascia lata, vastus lateralis, and rectus femoris muscles. (B) Relative size of neophallus, showing flap donor site with skin graft, skin graft donor site on contralateral leg, and optional connecting scar from flap donor site to inset in pedicled technique.

CFA: common femoral artery; LCFN: lateral femoral cutaneous nerve; LFCA: lateral femoral circumflex artery; PF: profunda femoris; SFA: superficial femoral artery. 
It is a good alternative for patients who do not qualify for a RFF due to a positive Allen's test or previous forearm surgery. Ideal patients should have a thigh pinch thickness $<1.5 \mathrm{~cm}$ if a singlestage urethral lengthening is planned; otherwise, patients should undergo a two-stage approach. ${ }^{32}$

The free ALT phalloplasty was initially reported as an alternative to the RFF. ${ }^{28}$ The authors specifically recommended a triangular skin flap on the pubic area with a distal $3 \mathrm{~cm}$ base and vertex $4 \mathrm{~cm}$ proximally at the midline. This allows the tubularised ALT to remain loosely approximated at the base of the neophallus to minimise pedicle compression and avoid flap defatting which can compromise circulation and sensation. The free ALT phalloplasty flap is rectangular, between $10 \times 12$ and $11 \times 14 \mathrm{~cm}$. The vascular pedicle is the descending branch of the lateral circumflex femoral artery. The ALT should be harvested from medial to lateral to preserve perforators through the vastus lateralis and superficial sensory branches of the lateral femoral cutaneous nerve. ${ }^{30}$ Flap reinnervation is via the dorsal pudendal nerve or ilioinguinal nerve. The typical recipient vessels are the same as with $\mathrm{RFF}^{28}$ To minimise urethral stricture, triangular flaps from the neourethra interdigitate with the native urethra. ${ }^{30}$ The pedicle must be monitored for compression during tubularisation of the flap.

If the flap does not use a tube-in-tube urethroplasty, ${ }^{14}$ the perineal tissue can be used to construct a lining flap for the neourethra. The base of the flap for the neourethra is immediately above the clitoris; a $2 \times 14 \mathrm{~cm}$ flap is created in the space between the clitoris and labia minora. ${ }^{28}$ It is rolled around an 18 French units (Fr) catheter and transposed upward to line the single-tube ALT flap. The donor site is closed primarily. After 6-12 months, the second stage can proceed with the neourethra anastomosis to the native urethra in the same setting as erectile prosthesis implantation.

An alternative to a free ALT flap is a pedicled ALT flap, which offers similar benefits without the need for microvascular anastomosis (Figure 2). ${ }^{30,33,34}$ The flap is raised as described above. To maximise lateral circumflex femoral artery pedicle length via the descending branch, the included perforators should be as distal as possible (until 5-6 $\mathrm{cm}$ proximal to the superior patella edge), and the pedicle dissected to the origin at the profunda femoris artery. ${ }^{32} \mathrm{~A}$ tunnel is created beneath the rectus femoris that becomes subcutaneous at the medial edge of the sartorius and the flap is carefully passed through the tunnel. ${ }^{30,35}$ The dorsal pudendal nerve or ilioinguinal nerve is identified and neurorrhaphy performed to the preserved lateral femoral cutaneous nerve on the ALT flap. Although penile implants are typically placed in a later stage, immediate placement has been described with a chimeric flap design incorporating a $3 \mathrm{~cm}$ strip of fascia lata to wrap the implant. ${ }^{33,36}$ A modification to the flap design using a semicircular extension at the distal portion, known as the mushroom flap, resembles more closely the glans of the native male penis, ${ }^{37}$ but may add excessive bulk in all but the thinnest patients.

Tissue expansion of the donor site may minimise scarring and need for skin grafting, as well as improve the flap perforator's vascular territory. ${ }^{35}$ Expansion takes between 4 weeks to 6 months. This can allow primary closure and minimisation of donor site contour deformities, avoiding the need for fat grafting. ${ }^{35}$ Other authors have urged caution, however, with an expander complication rate of $53 \%$ for pre-expanded RFF and ALT flaps, and only a $31 \%$ primary closure rate of the donor site. ${ }^{38}$

Complete flap loss is rare; however, partial flap loss does occur and can be morbid. ${ }^{32}$ It often involves the periphery of the flap (distal tip or base) and in areas where the tissue is folded on itself, such as the neourethra. Other outcomes have shown that the majority of patients can urinate standing (66.7\%), are capable of penetrative intercourse (60.0\%), and satisfied with the neophallus (100.0\%); while the most common complications are fistula formation (22.2\%) and stricture or stenosis $(6.7 \%)^{2}$

\section{Metoidioplasty}

Metoidioplasty, first described in 1996, ${ }^{39}$ comes closest to the reconstructive surgery concept of replacing 'like with like'. It uses the tissues of the external female genitalia to recreate their male analogs, paralleling the developmental processes that give rise to male external genitalia. The clitoris is first hypertrophied using systemic testosterone therapy. The clitoris is then surgically lengthened in a manner similar to chordee repair, with urethral reconstruction requiring the use of mucosal flaps 
or grafts, combined with local clitoral skin or labial flaps. Scrotoplasty and scrotal implants can be performed in the same stage or later. ${ }^{40,41}$

The operation begins by degloving the clitoris through a transcoronal incision and transecting the clitoral suspensory ligaments. Great care must be taken not to damage the dorsal clitoral nerve or the corpora cavernosa. The urethral plate is divided between urethral plate and clitoris to repair the chordee and allow lengthening of the neophallus. In a simple metoidioplasty, no urethroplasty is performed. This variant allows erogenous sensation and the appearance of a microphallus, but does not allow standing micturition. ${ }^{40}$

More complete metoidioplasty can be performed using several techniques. Ring metoidioplasty involves lengthening of the ventral urethral plate by the interposition of a 'ring flap' from the inner surfaces of the labia minora and a proximal neourethral flap of vaginal epithelium (Figure 3). This is then closed over a Foley catheter flaps to form a longer tubular structure. This repairs both the clitoral chordee and hypospadias, and therefore allows standing micturition. ${ }^{42}$
The 'Belgrade' metoidioplasty achieves further urethral lengthening using a buccal mucosal flap to lengthen the ventral urethral plate, followed by a closure with a longitudinal dorsal clitoral skin flap ${ }^{43}$ or labial flaps. ${ }^{44}$

In a direct comparison, final closure with labia minora flaps achieved greater urethral length of $10.8 \mathrm{~cm}$, as well as higher percentage of voiding while standing, and lower incidence of fistula compared with dorsal clitoral skin flap. ${ }^{45}$ Major complications include urethral fistula (7-15\%) and stricture (2-3\%). ${ }^{40,46}$ Initial assumptions about metoidioplasty outcomes have not been universally borne out. Twentyfour percent of Belgrade metoidioplasty patients underwent additional phalloplasty procedures in long-term follow-up, leading the authors to conclude that it could not be considered a true single-stage procedure. ${ }^{47}$ It was also initially believed that metoidioplasty would not allow penetrative intercourse; ${ }^{39}$ however, up to $53 \%$ of metoidioplasty patients report successful penetration in recent studies."

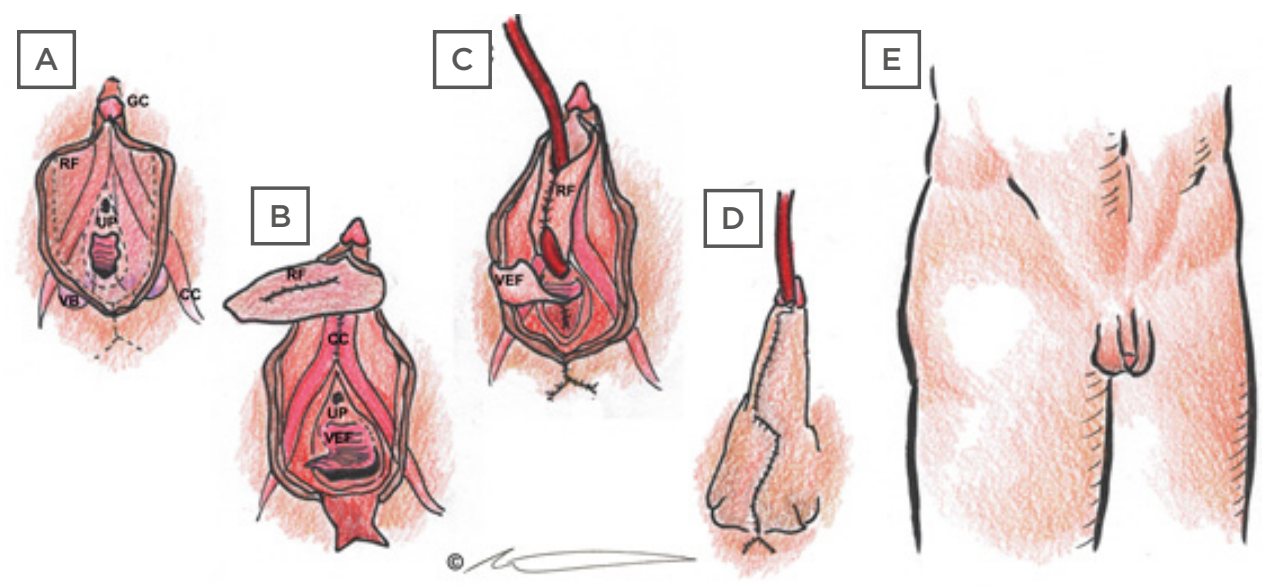

Figure 3: Schematic views of metoidioplasty using labial ring flap.

(A) Anatomy of natal female after hormone induced clitoral hypertrophy, showing glans clitoris, ring flap from labia minora inner surface, urethral plate, crus clitoris/corpus cavernosum, and vestibular bulb. (B) Elevation of ring flap after excision of vestibular bulb and midline suture of corpora cavernosa, with partial elevation of vaginal epithelial flap. (C) Full elevation of vaginal epithelial flap in preparation for anastomosis to ring flap, which has been tubularised around a Foley catheter. (D) Completed metoidioplasty with external surfaces of labia minora closed to form external surface of neophallus. (E) Relative size of metoidioplasty and scrotoplasty.

CC: corpus cavernosum; GC: glans clitoris; RF: ring flap; UP: urethral plate; VB: vestibular bulb; VEF: vaginal epithelial flap. 


\section{Other Surgical Techniques}

While the above techniques have become the preferred approaches for penile reconstruction, several other techniques have previously been used. These include the suprapubic phalloplasty, groin flaps, latissimus, free fibula flap, and transplantation.

The suprapubic phalloplasty is typically a multistage procedure. ${ }^{48,49}$ The first stage involves design of the flap where the base of the flap is near the desired location of the penis, ideally including the superficial external pudendal vessels, prior to tubularisation of the abdominal skin. The second stage creates the neourethra from perineal epithelium or clitoris. Additional stages may involve tissue expansion prior to flap design and keeping the tubularised flap attached in the first stage and then releasing the abdominal skin of the neophallus on one side. ${ }^{49}$

The groin flap can be performed as a one or twostage operation. For the single-stage operation, the groin flap can include the superficial circumflex iliac artery and the posterosuperior iliac spine to create a composite flap where the iliac crest bone provides rigidity. ${ }^{50}$ This composite flap is tubed around the neourethra, tunnelled from the donor site to the pubic symphysis, with the neourethra anastomosed to the native urethra in the same stage. The two-step procedure uses the superficial circumflex iliac artery and deep circumflex iliac artery, ${ }^{50}$ which provides the blood supply to the mobilised iliac bone. ${ }^{51}$ A prefabricated urethra from a full thickness skin graft is placed within the composite flap and the surrounding soft tissue is tubularised with the superior and inferior edges remaining attached. The second stage divides the superior edge and transposes the flap to the pubic region. Suprapubic and groin flaps have fallen out of favour because of inconsistency for sensation, atrophy of the neophallus, limited ability for standing micturition, and inability to engage in sexual intercourse. ${ }^{49,50}$

The latissimus dorsi muscle has been used as a functional pedicled musculocutaneous flap or free innervated flap. ${ }^{2}$ The innervated flap requires tonic contraction for erection formation. ${ }^{52}$ In addition, the flap does not allow for a tubewithin-a-tube penile urethra and often requires several stages. ${ }^{53}$
The osteocutaneous free fibula flap provides an autologous option that achieves the rigidity of a penile implant. ${ }^{2}$ Sensation is provided via the lateral or posterior sural cutaneous nerves that are harvested with the peroneal artery. The neourethra is prefabricated and inserted in a subcutaneous plane along the lateral leg where the planned osteocutaneous fibula flap will be taken. In the second stage, the osteocutaneous fibula flap is wrapped around the neourethra and transferred to the pubic region. It can be difficult to anchor the fibula to the pubic bone, and over time the fibula is prone to atrophy. ${ }^{54}$ Because of these disadvantages it is less commonly employed. As with other techniques, urethral stricture is the most common complication.

Vascularised composite penile transplantation has rarely been performed. It is the most complex of all the options for phalloplasty reconstruction, but can provide near-normal erections with orgasm and urinary transport. ${ }^{55,56}$

\section{Penile Implants}

While penile implants are commonly used for erectile dysfunction in native males, their application to reconstructive phalloplasty involves additional challenges. ${ }^{57}$ Protective sensation of the neophallus is required to avoid peri-implant trauma resulting in infection or exposure. Therefore, any flap being considered for implants must be successfully neurotised. The implant must also have a stable tissue bed to support the construct. In a natal male, the implant is contained within the corpora cavernosa and supported by the proximal penis. In reconstructive phalloplasty, the implant must be anchored, usually with a hinged or flexible construct to the pubis. As with other penile implants, implants for phalloplasty may be inflatable or semi-rigid. Complication rates are high: in a series of 1,056 patients, 36\% experienced complications, only $84 \%$ achieved penetration, and only $60 \%$ still had their original implant at a mean follow-up of 3 years. New device development is already focussing on these unique considerations, and specific prostheses are being tested for use after phalloplasty. ${ }^{58}$ 
Table 1: Summary of advantages and disadvantages to common methods of penile reconstruction.

\begin{tabular}{|c|c|c|}
\hline Operation & Advantages & Disadvantages \\
\hline Radial forearm free flap & $\begin{array}{l}\text { Good size match for natural } \\
\text { appearing neophallus } \\
\text { Tube-in-tube urethral reconstruction }\end{array}$ & $\begin{array}{l}\text { Forearm donor site scar, possible } \\
\text { pain and functional morbidity } \\
\text { Higher reported urethral } \\
\text { complication rate }\end{array}$ \\
\hline Metoidioplasty & $\begin{array}{l}\text { Reliable erogenous sensation and } \\
\text { ability to orgasm } \\
\text { Lower complication rate } \\
\text { Inherent erectile function } \\
\text { No secondary donor site } \\
\text { Ability to convert to phalloplasty } \\
\text { later } \\
\text { (Possibly) improved standing } \\
\text { micturition and ability to achieve } \\
\text { penetration }\end{array}$ & Microphallus appearance \\
\hline Anterolateral thigh flap & $\begin{array}{l}\text { May be used as pedicled flap } \\
\text { Large neophallus without forearm } \\
\text { donor site }\end{array}$ & $\begin{array}{l}\text { Decreased sensation } \\
\text { Increased bulk } \\
\text { Single stage and tube in tube } \\
\text { urethral reconstruction generally not } \\
\text { possible }\end{array}$ \\
\hline
\end{tabular}

\section{DISCUSSION}

\section{Choice of Reconstructive Method}

Overall patient satisfaction after phalloplasty is high. ${ }^{2}$ The increasing awareness of phalloplasty is also improving available patient information and helping to educate patients preoperatively, leading to more informed decisions. ${ }^{59}$ Radial forearm appears to be the new standard in phalloplasty, followed by metoidioplasty and ALT flap (Table 1). Few studies have attempted to directly compare the outcomes of different methods. One metaanalysis comparing metoidioplasty with RFF revealed respective $87 \%$ versus $70 \%$ aesthetic satisfaction, 0.43 versus 0.88 complication per patient, $100 \%$ versus $69 \%$ erogenous sensation, $53 \%$ versus $43 \%$ ability to achieve penetration, and $89.1 \%$ versus $75.0 \%$ standing micturition." The ALT flap is essentially a second-line option for patients who would like a larger neophallus but want to avoid a forearm donor site, and are relatively thin.
In interpreting subjective outcomes of phalloplasty (especially aesthetics), self-selection by patients must be given significant weight.

While complication and functional profiles do differ between different methods, fundamentally each of the major choices will have a different aesthetic outcome, and the patient who chose a particular method will have done so with that outcome in mind.

The radial forearm usually comes closest in appearance to a natural-appearing phallus but has a significant aesthetic donor-site morbidity that must be acceptable to the patient. The metoidioplasty may have the best functional outcomes, but in appearance resembles a microphallus. The ALT flap is too thick to support tube-in-tube neourethra creation in all but the thinnest patients, and even then, may have excessive girth to be aesthetically acceptable to some. 


\section{Avoiding Urethral Complications}

Urethral complications (leak and stricture) bear special mention as the most common problem with penile reconstruction. 2,24,27,60 Strategies for avoidance of urethral complications involve basic surgical principles of avoiding of tension and optimising perfusion to the urethral segment. With tube-in-tube designs, perfusion can be improved by including secondary venous drainage on the urethral portion of ulnar side of the forearm, by fashioning the urethral segment of the flap longer proximally, and by leaving a cuff of fat even more proximal to this to avoid devascularising the proximal skin edge. Recent data suggests that single-stage urethroplasty ${ }^{60}$ and the use of paravaginal tissue flaps ${ }^{27}$ may also decrease the incidence of urethral complications.

\section{CONCLUSION}

Penile reconstruction has matured considerably over the last decades in reconstructive options and technical refinements, thanks to increasing recognition of gender dysphoria. Free RFF, ALT flap, and metoidioplasty are the most common options, each with a unique profile of complications, aesthetic, and functional outcomes. Urethral complications remain the largest barrier to operative success. Choices for reconstruction must be tailored to the individual patient's goals and available tissue characteristics. Analysis of the larger numbers of penile reconstructions now being performed will enable ongoing improvement in outcomes and better options for patients.

\section{References}

1. Yao A et al. Total penile reconstruction: a systematic review. $J$ Plast Reconstr Aesthet Surg. 2018;71(6):788-806.

2. Morrison SD et al. Phalloplasty: a review of techniques and outcomes. Plast Reconstr Surg. 2016;138(3):594615.

3. Balzano FL, Hudak SJ. Military genitourinary injuries: past, present, and future. Transl Androl Urol. 2018;7(4):646-52.

4. Massanyi EZ et al. Radial forearm free flap phalloplasty for penile inadequacy in patients with exstrophy. J Urol. 2013;190(4 Suppl):1577-82.

5. Lane $\mathrm{M}$ et al. Trends in genderaffirming surgery in insured patients in the united states. Plast Reconstr Surg Glob Open. 2018;6(4):e1738.

6. Canner JK et al. Temporal trends in gender-affirming surgery among transgender patients in the United States. JAMA Surg. 2018;153(7):60916.

7. Ganor O et al. Piloting a genital affirmation surgical priorities scale for trans masculine patients. Transgend Health. 2019;4(1):270-6.

8. Hage JJ, De Graaf FH. Addressing the ideal requirements by free flap phalloplasty: some reflections on refinements of technique. Microsurgery. 1993;14(9):592-8.

9. Coleman E et al. Standards of care for the health of transsexual, transgender, and gender-nonconforming people, version 7. Int J Transgend. 2012;13:165232.
10. Ngaage LM et al. The Baltimore criteria for an ethical approach to penile transplantation: a clinical guideline. Transpl Int. 2019.[Epub ahead of print].

11. Frey JD et al. A systematic review of metoidioplasty and radial forearm flap phalloplasty in female-to-male transgender genital reconstruction: is the "ideal" neophallus an achievable goal? Plast Reconstr Surg Glob Open. 2016;4(12):e1131.

12. Biemer E. Penile construction by the radial arm flap. Clin Plast Surg. 1988;15(3):425-30.

13. Chang TS, Hwang WY. Forearm flap in one-stage reconstruction of the penis. Plast Reconstr Surg. 1984;74(2):251-8.

14. Gottlieb LJ. Radial forearm. Clin Plast Surg. 2018;45(3):391-8.

15. Gottlieb LJ, Levine LA. A new design for the radial forearm free-flap phallic construction. Plast Reconstr Surg. 1993;92(2):276-83; discussion 284

16. Monstrey $\mathrm{S}$ et al. Penile reconstruction: is the radial forearm flap really the standard technique? Plast Reconstr Surg. 2009;124(2):5108.

17. Kim S-K et al. Phalloplasty using radial forearm osteocutaneous free flaps in female-to-male transsexuals. $\mathrm{J}$ Plast Reconstr Aesthet Surg. 2009;62(3):309-17.

18. Gilbert DA et al. Phallic reinnervation via the pudendal nerve. J Urol. 1988;14O(2):295-9.

19. Selvaggi G, Bellringer J. Gender reassignment surgery: an overview.
Nat Rev Urol. 2011;8(5):274-82

20. De Cuypere $\mathrm{G}$ et al. Long-term follow-up: psychosocial outcome of Belgian transsexuals after sex reassignment surgery. Sexologies. 2006;15(2):126-33.

21. De Cuypere $\mathrm{G}$ et al. Sexual and physical health after sex reassignment surgery. Arch Sex Behav. 2005;34(6):679-90.

22. Selvaggi $G$ et al. Genital sensitivity after sex reassignment surgery in transsexual patients. Ann Plast Surg. 2007;58(4):427-33.

23. Hoebeke PB et al. Erectile implants in female-to-male transsexuals: our experience in 129 patients. Eur Urol. 2010;57(2):334-40

24. Ascha M et al. Outcomes of single stage phalloplasty by pedicled anterolateral thigh flap versus radial forearm free flap in gender confirming surgery. J Urol. 2018;199(1):206-14.

25. Kovar A et al. Donor site morbidity in phalloplasty reconstructions: outcomes of the radial forearm free flap. Plast Reconstr Surg Glob Open. 2019;7(9):e2442.

26. Van Caenegem E et al. Long-term evaluation of donor-site morbidity after radial forearm flap phalloplasty for transsexual men. J Sex Med. 2013;10(6):1644-51.

27. Santucci RA. Urethral complications after transgender phalloplasty: strategies to treat them and minimize their occurrence. Clinical Anatomy. 2018;31(2):187-90.

28. Felici N, Felici A. A new phalloplasty 
technique: the free anterolateral thigh flap phalloplasty. J Plast Reconstr Aesthet Surg. 2006;59(2):153-7.

29. Terrell M et al. Anatomy of the pedicled anterolateral thigh flap for phalloplasty in transitioning-males. Clin Anat. 2018;31(2):160-8.

30. Lee GK et al. A novel singleflap technique for total penile reconstruction: the pedicled anterolateral thigh flap. Plast Reconstr Surg. 2009;124(1):163-6.

31. Lin SJ et al. Designing the anterolateral thigh flap without preoperative Doppler or imaging. J Reconstr Microsurg. 2010;26(1):67-72.

32. Xu KY, Watt AJ. The pedicled anterolateral thigh phalloplasty. Clin Plast Surg. 2018;45(3):399-406.

33. Rubino $\mathrm{C}$ et al. Innervated island pedicled anterolateral thigh flap for neo-phallic reconstruction in femaleto-male transsexuals. J Plast Reconstr Aesthet Surg. 2009;62(3):e45-9.

34. Descamps MJL et al. Phalloplasty in complete aphallia: pedicled anterolateral thigh flap. J Plast Reconstr Aesthet Surg. 2009;62(3):e51-4

35. D'Arpa S et al. Pre-expanded anterolateral thigh perforator flap for phalloplasty. Clin Plast Surg. 2017;44(1):129-41.

36. Mutaf $\mathrm{M}$ et al. A true one-stage nonmicrosurgical technique for total phallic reconstruction. Ann Plast Surg. 2006:57(1):100-6.

37. Morrison SD et al. Modification of the tube-in-tube pedicled anterolateral thigh flap for total phalloplasty: the mushroom flap. Ann Plast Surg. 2014;72(Suppl 1):S22-6.

38. Elfering $L$ et al. Preexpansion in phalloplasty patients: is it effective? Ann Plast Surg. 2019;83(6):687-92

39. Hage JJ. Metaidoioplasty: an alternative phalloplasty technique in transsexuals. Plast Reconstr Surg. 1996;97(1):161-7.

40. Djordjevic ML et al. Metoidioplasty: techniques and outcomes. Trans Androl Urol. 2019:8(3):248-53.

41. Djinovic RP. Metoidioplasty. Clin Plast Surg. 2018;45(3):381-6.

42. Takamatsu A, Harashina T. Labial ring flap: a new flap for metaidoioplasty in female-to-male transsexuals. J Plast Reconstr Aesthet Surg. 2009;62(3):318-25.

43. Perovic SV, Djordjevic ML. Metoidioplasty: a variant of phalloplasty in female transsexuals. BJU International. 2003:92(9):981-5.

44. Djordjevic ML et al. Urethra lengthening in metoidioplasty (female-to-male sex reassignment surgery) by combined buccal mucosa graft and labia minora flap. Urology. 2009;74(2):349-53.

45. Djordjevic ML, Bizic MR. Comparison of two different methods for urethral lengthening in female to male (metoidioplasty) surgery. J Sex Med. 2013;10(5):1431-8.

46. Nikolavsky D et al. Urologic complications after phalloplasty or metoidioplasty. Clin Plast Surg. 2018:45(3):425-35

47. Hage JJ, van Turnhout AAWM. Longterm outcome of metaidoioplasty in 70 female-to-male transsexuals. Ann Plast Surg. 2006;57(3):312-6.

48. Bettocchi $\mathrm{C}$ et al. Pedicled pubic phalloplasty in females with gender dysphoria. BJU Int. 2005;95(1):120-4.

49. Terrier J-É et al. Surgical outcomes and patients' satisfaction with suprapubic phalloplasty. J Sex Med. 2014;11(1):288-98.

50. Sun GC, Huang JJ. One-stage reconstruction of the penis with composite iliac crest and lateral groin skin flap. Ann Plast Surg. 1985;15(6):519-28.
51. Aköz T, Kargi E. Phalloplasty in a female-to-male transsexual using a double-pedicle composite groin flap. Ann Plast Surg. 2002;48(4):423-7; discussion 427

52. Vesely $\mathrm{J}$ et al. New technique of total phalloplasty with reinnervated latissimus dorsi myocutaneous free flap in female-to-male transsexuals. Ann Plast Surg. 2007;58(5):544-50.

53. Perovic SV et al. Total phalloplasty using a musculocutaneous latissimus dorsi flap. BJU Int. 2007;100(4):899-905; discussion 905

54. Ruff C et al. Who's afraid of the big bad Wolff?: "'Wolff's Law”' and bone functional adaptation. Am J Phys Anthropol. 2006;129:484-98.

55. Redett RJ et al. Total penis, scrotum, and lower abdominal wall transplantation. N Engl J Med. 2019;381(19):1876-8.

56. Sopko NA et al. Penile allotransplantation for complex genitourinary reconstruction. J Urol. 2017;198(2):274-80.

57. Rooker SA et al. The rise of the neophallus: a systematic review of penile prosthetic outcomes and complications in gender-affirming surgery. J Sex Med. 2019;16(5):661-72.

58. Neuville P et al. First outcomes of the ZSI 475 FtM, a specific prosthesis designed for phalloplasty. J Sex Med. 2019;16(2):316-22.

59. van de Grift TC et al. Surgical satisfaction, quality of life, and their association after gender-affirming surgery: a follow-up study. J Sex Marital Ther. 2018;44(2):138-48.

60. Remington $A C$ et al. Outcomes after phalloplasty: do transgender patients and multiple urethral procedures carry a higher rate of complication? Plast Reconstr Surg. 2017;141(2):220e9e. 